\title{
Effect of Run Training and Cold-Water Immersion on Subsequent Cycle Training Quality in High-Performance Triathletes
}

\author{
Greg J. Rowsell, ${ }^{1}$ Peter Reaburn, ${ }^{2}$ Rebecca Toone, ${ }^{1}$ Mitchell Smith, ${ }^{3}$ and Aaron J. Coutts ${ }^{3}$ \\ ${ }^{1}$ South Australian Sports Institute, Kidman Park, Australia; ${ }^{2}$ Health $\&$ Human Performance, CQUniversity, Rockhampton, \\ Australia; and ${ }^{3}$ Sport and Exercise Discipline Group, UTS: Health, University of Technology, Sydney, Australia
}

\begin{abstract}
Rowsell, GJ, Reaburn, P, Toone, R, Smith, M, Coutts, AJ. Effect of run training and cold-water immersion on subsequent cycle training quality in high-performance triathletes. J Strength Cond Res 28(6): 1664-1672, 2014-The purpose of the study was to investigate the effect of cold-water immersion (CWI) on physiological, psychological, and biochemical markers of recovery and subsequent cycling performance after intensive run training. Seven high-performance male triathletes (age: $28.6 \pm 7.1$ years; cycling $\dot{V}_{2}$ peak: $73.4 \pm$ $10.2 \mathrm{ml} \cdot \mathrm{kg}^{-1} \cdot \mathrm{min}^{-1}$ ) completed 2 trials in a randomized crossover design consisting of $7 \times 5$-minute running intervals at $105 \%$ of individual anaerobic threshold followed by either $\mathrm{CWI}\left(10 \pm 0.5^{\circ} \mathrm{C}\right)$ or thermoneutral water immersion (TNI; $\left.34 \pm 0.5^{\circ} \mathrm{C}\right)$. Subjects immersed their legs in water 5 times for 60 seconds with 60-second passive rest between each immersion. Nine hours after immersion, inflammatory and muscle damage markers, and perceived recovery measures were obtained before the subjects completed a 5-minute maximal cycling test followed by a high-quality cycling interval training set $(6 \times 5$-minute intervals). Power output, heart rate, blood lactate (La), and rating of perceived exertion (RPE) were also recorded during the cycling time-trial and interval set. Performance was enhanced (change, $\pm 90 \%$ confidence limits) in the $\mathrm{CWI}$ condition during the cycling interval training set (power output $\left[\mathrm{W} \cdot \mathrm{kg}^{-1}\right.$ ], $2.1 \pm 1.7 \%$, La $\left[\mathrm{mmol} \cdot \mathrm{L}^{-1}\right], 18 \pm 18.1 \%$, La:RPE, $19.8 \pm 17.5 \%)$. However, there was an unclear effect of $\mathrm{CWI}$ on 5-minute maximal cycling time-trial performance, and there was no significant influence on perceptual measures of fatigue/recovery, despite small to moderate effects. The effect of CWI on the biochemical markers was mostly unclear, however, there was a substantial effect for interleukin-10 (20 \pm 13.4\%). These results suggest that compared with TNI, CWI
\end{abstract}

Address correspondence to Aaron J. Coutts, aaron.coutts@uts.edu.au. 28(6)/1664-1672

Journal of Strength and Conditioning Research

(C) 2014 National Strength and Conditioning Association

1664

Journal of Strength and Conditioning Research may be effective for enhancing cycling interval training performance after intensive interval-running training.

KEY WoRDS recovery, hydrotherapy, muscle damage, intensive training

\section{INTRODUCTION}

I ntensive and prolonged training is generally accepted to be critical for enhancing the physical performance of high-level athletes. However, insufficient recovery from a single intense training session may leave the athlete unable to train at the required level during subsequent training sessions $(2,17)$. Therefore, effective recovery between successive training bouts is widely acknowledged as important for training performance at the next training session.

Cold-water immersion (CWI) is a popular strategy for enhancing recovery in high-level athletes $(23,35)$. It is routinely advocated as beneficial for enhancing both physiological and psychological recovery after exercise, (36), particularly as it reduces delayed-onset muscle soreness $(6,23)$. Indeed, it has been suggested that CWI may be useful for enhancing subsequent training quality and ultimately competitive performance through improved recovery and the accumulative effects of increased quality and quantity of training (2). However, despite the popularity and increasing prevalence of CWI as a recovery modality, its effect on recovery and subsequent performance of high-level athletes remains somewhat unclear $(27,34)$.

The results of research into the possible benefits of CWI for enhancing athlete recovery from intensive previous exercise, training, or competition are varied. Cold-water immersion has been shown to improve $(20,22,29,35,40)$, impair (11,33), and have no effect on performance (34). Yeargin et al. (40) demonstrated that 2-mile running performance improved by $6 \%$ after 12 minutes of CWI at approximately $14^{\circ} \mathrm{C}$ completed after a 90 -minute run in the heat (approximately $27^{\circ} \mathrm{C}$ ) at a "challenging, yet comfortable" pace. In contrast, 15 minutes of CWI at $13-14^{\circ} \mathrm{C}$ has been shown to impair sprint cycling performance (11) and attenuate the adaptive processes achieved through improved 
TABLE 1. Effects of cold-water immersion (relative to thermoneutral immersion) after intensive running training on mean change in cycling performance.

\begin{tabular}{|c|c|c|c|c|c|}
\hline \multirow[b]{2}{*}{ Measure } & \multirow[b]{2}{*}{$\begin{array}{c}\text { Mean change, } \\
\%\end{array}$} & \multirow[b]{2}{*}{$\begin{array}{c}90 \% \text { confidence limits, } \\
\%\end{array}$} & \multicolumn{3}{|c|}{$\begin{array}{l}\text { Chances that the true effect is } \\
\text { substantial }{ }^{*}\end{array}$} \\
\hline & & & $\begin{array}{l}\text { Benefit, } \\
\quad \%\end{array}$ & $\begin{array}{l}\text { Harm, } \\
\quad \%\end{array}$ & $\begin{array}{c}\text { Practical } \\
\text { assessment } \dagger\end{array}$ \\
\hline \multicolumn{6}{|l|}{$\begin{array}{l}\text { Effect on } 5 \text {-minute TT } \\
\text { performance }\end{array}$} \\
\hline Mean power output $\left(\mathrm{W} \cdot \mathrm{kg}^{-1}\right)$ & 1.5 & 1.7 & 4 & 10 & Benefit very unlikely \\
\hline \multicolumn{6}{|l|}{ Effect on training set } \\
\hline Mean power output $\left(\mathrm{W} \cdot \mathrm{kg}^{-1}\right)$ & 2.1 & 1.7 & 78 & 0 & Benefit likely \\
\hline $\mathrm{La}\left(\mathrm{mmol} \cdot \mathrm{L}^{-1}\right)$ & 18 & 18.1 & 86 & 2 & Benefit likely \\
\hline HR (bpm) & 1.6 & 1.1 & 74 & 0 & Benefit possible \\
\hline RPE (6-20 scale) & -1.6 & 1.9 & 2 & 77 & Benefit likely \\
\hline La:RPE & 19.8 & 17.5 & 90 & 1 & Benefit likely \\
\hline$\dot{\mathrm{V}} \mathrm{O}_{2}$ peak & & & & & \\
\hline
\end{tabular}

blood supply after arm and leg training (39). Furthermore, CWI has been reported to have no effects on cycling 15-minute time-trial performance after 60 minutes of high-intensity cycling (34). Collectively, these results suggest that the effects of CWI are dependent on exercise demands and the length of time between immersion and exercise.

Because the effects of CWI are largely dependent on the type of exercise undertaken and the length of time between bouts (16), it is important that investigations accurately represent real sport-specific environments. Indeed, a few studies have reported an enhanced ability to maintain performance after CWI during actual $(13,25,31,32)$ or simulated $(20,29)$ competition. In a study of basketball athletes during a 3-day tournament, Montgomery et al. (25) observed an improved maintenance of 20-m sprint acceleration, line drill, vertical jump, and sit and reach performance using CWI between matches. Others reported that CWI decreased perceptions of fatigue and soreness and blunted the reduction in distance run during matches in higher speed zones $\left(>15 \mathrm{~km} \cdot \mathrm{h}^{-1}\right)$ during a 4-day soccer tournament in elite youth players (32). In this investigation, CWI had no effects on physical performance tests (i.e., repeated sprint ability, vertical jump, and sprint ability) (31) compared with a matched thermoneutral immersion (TNI) treatment. Although the effect of CWI on recovery in a tournament scenario seems to offer some performance benefits, its efficacy as a recovery method during intensive training periods is less clear. Of particular interest is whether CWI enhances recovery during the typical twice-daily training routine of elite level athletes, such as triathletes.

During twice-daily training, it is important to use appropriate recovery strategies, as there is minimal time for recovery and the possibility of overtraining is increased (21). Moreover, the muscle damage that can occur after exercise is associated with a loss of muscle function and may impair performance in subsequent exercise bouts (8). Minimizing the extent of muscle damage after intense training may help accelerate the recovery process and enable the athlete to tolerate a higher training load in subsequent training (2). In fact, several studies have examined the effects of CWI on perceptual measures, muscle damage, and subsequent performance immediately after exercise (30), and up to 96 hours after immersion $(23,36)$. To the best of the authors' knowledge, however, no previous studies have investigated these markers of recovery during a typical twice-daily training routine in elite athletes.

Therefore, the purpose of this study was to investigate the effect of CWI on physiological, psychological, and biochemical markers of recovery and subsequent cycling performance after intensive running training in high-performance triathletes. It was hypothesized that compared with a TNI control condition, CWI would enhance cycling performance after intensive run training, in high-performance triathletes training twice a day. 


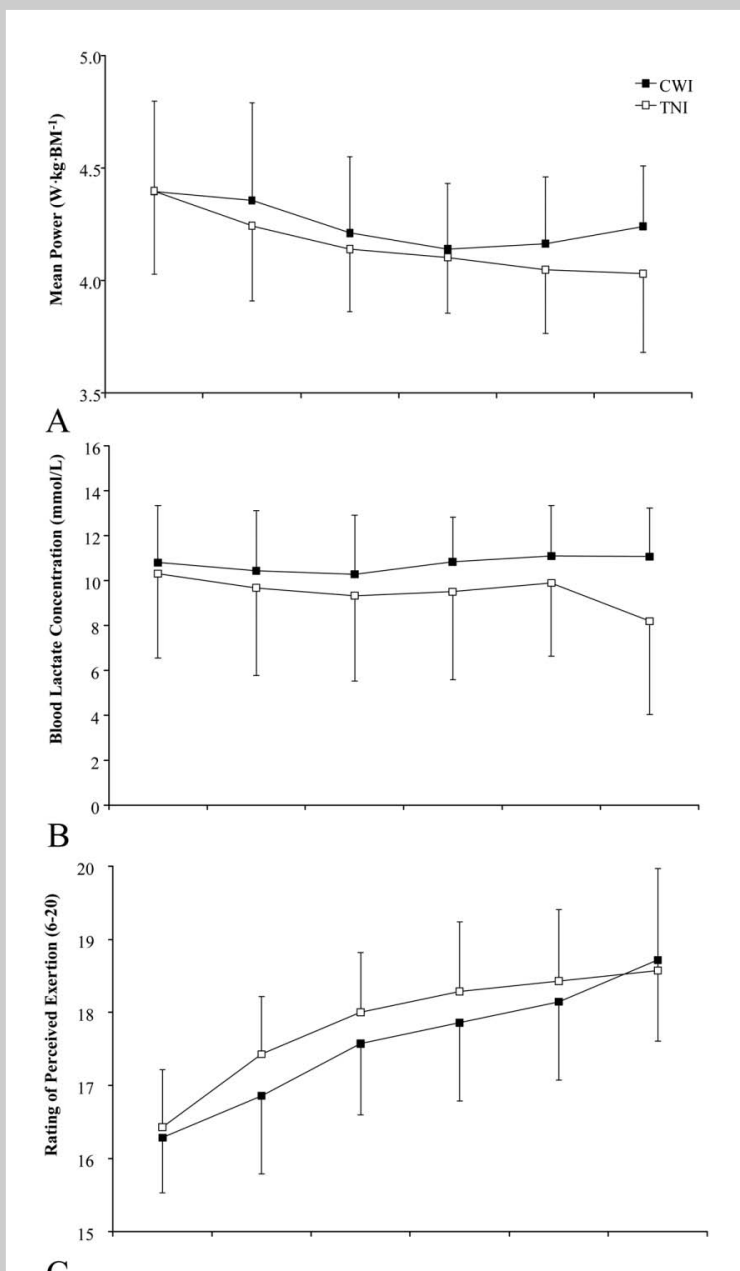

$\mathrm{C}$

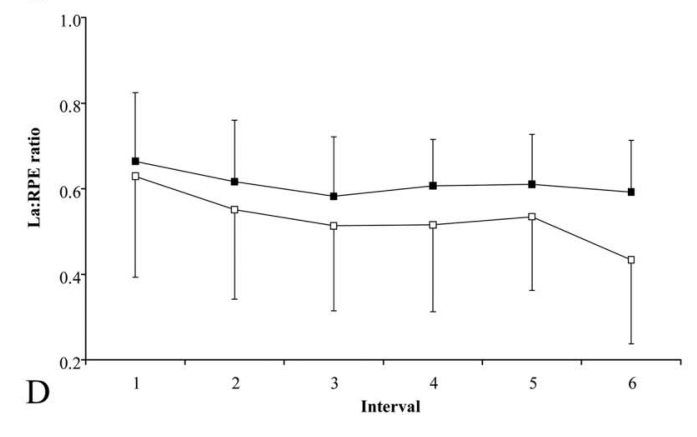

Figure 1. Effect of cold-water immersion (relative to thermoneutral immersion) after intensive running training on: (a) power output, (b) blood lactate concentration, and (c) Rating of Perceived Exertion (RPE) during a cycling interval training set.

\section{Methods}

\section{Experimental Approach to the Problem}

A counterbalanced crossover research design involving 2 trials was used to test the hypothesis that CWI is beneficial for recovery during twice-daily training typical of elite triathletes. Subjects completed 2 trials, 1 in the CWI condition and 1 in the TNI control condition with a 7-day washout period between trials. Subjects performed an interval running session, followed by water immersion at either $10 \pm 0.5^{\circ} \mathrm{C}$ or $34 \pm 0.5^{\circ} \mathrm{C}$. Nine hours after immersion, subjects completed a 5 -minute maximal effort cycling performance trial followed by a high-quality cycling interval training set. Particular interest was paid to the ability of athletes to maintain cycling performance after CWI in comparison with TNI. Additionally, perceptions of fatigue, recovery, and soreness as well as markers of muscle damage and inflammation were used to assess the recovery process (21). The recovery time, interval running session, and cycling interval training set were designed to reflect "real-life" training for high-level triathletes.

\section{Subjects}

Seven well-trained male triathletes (age: $28.6 \pm 7.1$ years; range: $18-40$ years; cycling $\dot{\mathrm{V}}_{2}$ peak: $73.4 \pm 10.2$ $\mathrm{ml} \cdot \mathrm{kg}^{-1} \cdot \mathrm{min}^{-1}$ ) volunteered to participate in the study. The triathletes were undertaking their normal training during the study and did not compete between test sessions. Subjects were previously unfamiliar with CWI and were free from known illness or injury. Ethical approval was obtained from the Central Queensland University Human Research Ethics Committee and all subjects provided written informed consent before their inclusion in the study. All experimental procedures followed the Helsinki declaration.

\section{Procedures}

The study required 6 visits to the South Australian Sports Institute (SASI, Adelaide, Australia) laboratory. The first 2 sessions were designed to record subject characteristics and necessary physiological data for experimental sessions. The remaining 4 sessions were considered the experimental sessions, with 2 sessions (interval running and highintensity cycling) being completed in each condition (CWI and TNI). The testing sessions in each condition were conducted on the same day, separated by 9 hours, with a 7-day washout period between conditions.

One week before the study, subjects completed the first session to determine individual anaerobic (IAT) and lactate threshold (LT) running velocities. The session consisted of an incremental running test on the SASI motorized treadmill (SASI). After a 5-minute warm-up at $8 \mathrm{~km} \cdot \mathrm{h}^{-1}$, the test commenced at $10 \mathrm{~km} \cdot \mathrm{h}^{-1}$ which was increased by 1.5 $\mathrm{km} \cdot \mathrm{h}^{-1}$ every 5 minutes until volitional exhaustion. Heart rate (Polar NV heart rate monitor, Polar Electro Oy, Oulu, Finland), blood lactate (La; Lactate Pro; Arkray Inc., Kyoto, Japan), and rating of perceived exertion (RPE; Borg 6-20) were measured in the last 15 seconds of each 5-minute workload. Individual anaerobic threshold and LT running velocity were calculated using the ADAPT software (version 3.8.0.1; Australian Sports Commission, Canberra, Australia). Lactate threshold was determined as the intensity preceding a 0.4 $\mathrm{mmol} \cdot \mathrm{L}^{-1}$ increase in La above the baseline (7). The IAT was determined as the point on the La-exercise intensity 


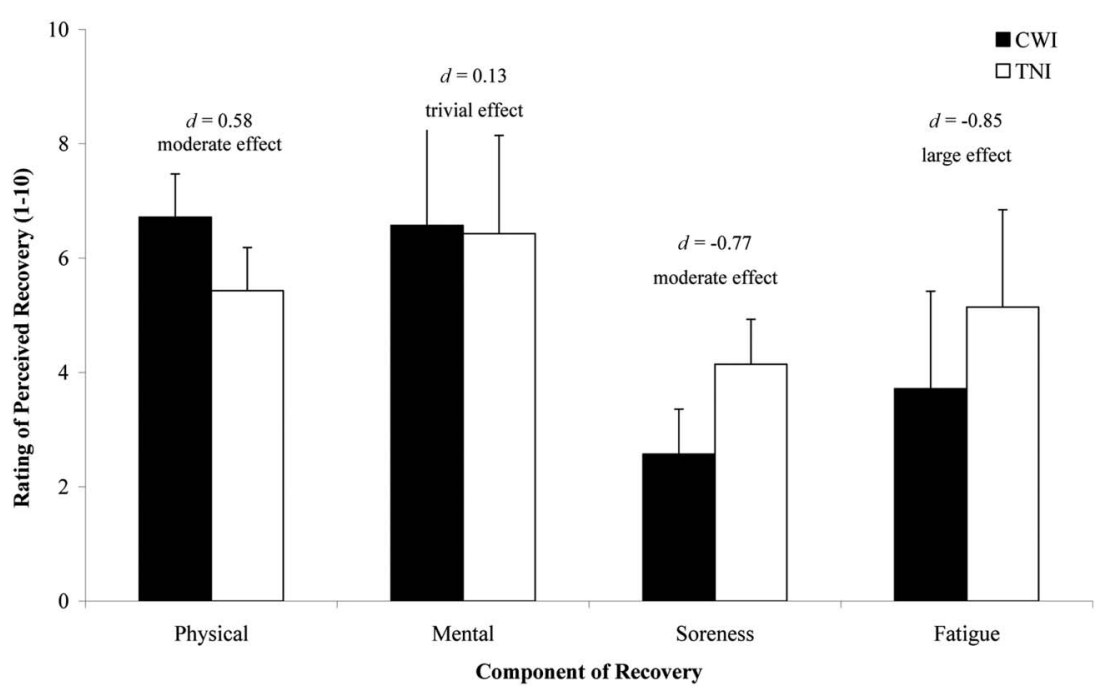

Figure 2. Effects of cold-water immersion (relative to thermoneutral immersion) after intensive running training on perception of mental and physical recovery, leg soreness, and fatigue. $d=$ Cohen's $d$ effect size

curve at maximal distance from a line connecting LT and finishing intensities (5).

Two days later, subjects completed a cycling performance test on the SASI cycling ergometer (SASI) to determine $\mathrm{V}_{2}$ peak. Subjects performed a 20 -minute warm-up that included 5 minutes at 1.5 and 5 minutes at $3 \mathrm{~W} \cdot \mathrm{kg}^{-1}$, as well as 10 minutes at a self-selected pace. After warm-up, subjects completed a 5-minute maximum effort cycling bout during which $\dot{V}_{O_{2}}$ peak was recorded as the highest 60 second average. Oxygen consumption was measured using the bespoke SASI gas analysis system (SASI), which was calibrated before each test.

In the 48 hours before and on the day of each testing session, the athletes followed a standardized eating plan, prepared and controlled by a sports dietician. This diet was designed to ensure adequate muscle glycogen stores and included approximately $10 \%$ fat, approximately $50 \%$ carbohydrate and approximately $40 \%$ protein. The athletes also abstained from intense exercise and caffeine in the 24 hours before each trial. Both experimental trials were completed at the same time of day (time) and under the same environmental conditions (approximately $21^{\circ} \mathrm{C}$ and approximately $40 \%$ relative humidity).

The first session in each experimental condition involved $7-\times 5$-minute running intervals on a motorized treadmill at $105 \%$ of the athletes previously determined IAT running velocity. During the 90 -second recovery periods between interval runs, subjects cycled on an air-braked cycling ergometer (SASI) at $1.5 \mathrm{~W} \cdot \mathrm{kg}^{-1}$. This protocol was chosen to replicate a typical precompetitive phase interval running session performed by these high-level triathletes who include low-intensity cycling for recovery between interval runs. All interval-running sessions were performed on the calibrated SASI laboratory treadmill (SASI) at a $1 \%$ grade after a 10-minute warm-up at the athlete's previously determined LT running velocity. At the end of the interval running session, each subject completed a 5-minute warm-down at their LT running velocity followed by 5 -minute of passive stretching. Subjects also consumed $200 \mathrm{ml}$ of milk-based recovery drink (Sustagen Sport; Mead Johnson and Co., IL, USA) containing $21 \mathrm{~g}$ of protein and $48 \mathrm{~g}$ of $\mathrm{CHO}$.

Subjects commenced the recovery, water immersion protocol 10 minutes after completion of the interval running session using a portable bath (Portacovery, Canberra, Australia). Subjects performed 5 alternating exposures of 60 seconds seated immersion (to the level of the iliocristale) in a cold bath $\left(10 \pm 0.5^{\circ} \mathrm{C}\right.$; CWI $)$ or thermoneutral bath $\left(34 \pm 0.5^{\circ} \mathrm{C}\right.$; TNI $)$ and 60 seconds seated rest on a chair at room temperature $\left(24^{\circ} \mathrm{C}\right)$. The water was repeatedly agitated to avoid formation of a warmer boundary layer, and water temperature was maintained by adding water or ice.

The athletes reported to the laboratory approximately 8.5 hours after the interval running session for the assessment of psychological and biochemical markers of recovery. Following the assessment of recovery, the athletes completed a 20minute warm-up on a purpose built, calibrated, track single chain ring, air-braked cycling ergometer (SASI). The warmup included 5 minutes at a workload of $1.5 \mathrm{~W} \cdot \mathrm{kg}^{-1}$, 5 minutes at $3 \mathrm{~W} \cdot \mathrm{kg}^{-1}$ and 10 minutes at a self-selected pace. Athletes then performed a 5-minute maximal effort performance test on the same cycling ergometer. After 10 minutes of recovery cycling at $1.5 \mathrm{~W} \cdot \mathrm{kg}^{-1}$, the athletes performed 
TABLE 2. Effects of cold-water immersion (relative to thermoneutral immersion) after intensive running training, on mean change in biochemical measures.

\begin{tabular}{|c|c|c|c|c|c|c|c|}
\hline \multirow[b]{2}{*}{ Measure } & \multirow[b]{2}{*}{$\begin{array}{l}\text { Thermoneutral } \\
\text { immersion }\end{array}$} & \multirow[b]{2}{*}{$\begin{array}{l}\text { Cold-water } \\
\text { immersion }\end{array}$} & \multirow[b]{2}{*}{$\begin{array}{c}\text { Mean } \\
\text { change, \% }\end{array}$} & \multirow[b]{2}{*}{$\begin{array}{l}90 \% \text { confidence } \\
\text { limits, } \%\end{array}$} & \multicolumn{3}{|c|}{$\begin{array}{c}\text { Chances that the true effect is } \\
\text { substantial* }\end{array}$} \\
\hline & & & & & $\begin{array}{l}\text { Benefit, } \\
\quad \%\end{array}$ & $\begin{array}{l}\text { Harm, } \\
\%\end{array}$ & $\begin{array}{c}\text { Practical } \\
\text { assessment } \dagger\end{array}$ \\
\hline FABP (pg/ml) & $6296 \pm 7763$ & $4652 \pm 4454$ & -8.4 & 24.7 & 13 & 30 & Unclear \\
\hline $\begin{array}{l}\text { Creatine kinase } \\
(\mathrm{U} / \mathrm{L})\end{array}$ & $377 \pm 119$ & $335 \pm 158$ & -12.4 & 49.2 & 16 & 61 & Unclear \\
\hline LDH (U/L) & $368 \pm 57$ & $386 \pm 81$ & 4.0 & 9.4 & 55 & 8 & Unclear \\
\hline $\begin{array}{l}\text { Myoglobin } \\
\text { (ng/ml) }\end{array}$ & $83 \pm 46$ & $62 \pm 31$ & -22.5 & 60.6 & 9 & 73 & Unclear \\
\hline $\begin{array}{l}\text { Interleukin-6 } \\
(\mathrm{pg} / \mathrm{ml})\end{array}$ & $1.34 \pm 1.20$ & $1.20 \pm 0.32$ & 13.4 & 104.0 & 48 & 23 & Unclear \\
\hline $\begin{array}{l}\text { Interleukin-10 } \\
\quad(\mathrm{pg} / \mathrm{ml})\end{array}$ & $1.07 \pm 0.30$ & $1.28 \pm 0.36$ & 20.0 & 13.4 & 94 & 1 & Likely beneficial \\
\hline
\end{tabular}

six 5 -minute freely paced cycling intervals separated by 60 second active recoveries cycling at $1.5 \mathrm{~W} \cdot \mathrm{kg}^{-1}$. The athletes were instructed to achieve the highest possible mean power output during the training set.

\section{Psychological Recovery}

On arrival to the laboratory for the second session, subjects were asked to record their perception of physical and mental recovery, leg soreness, and general fatigue using a 10 -point Likert scale. The scale for each variable was rated from none at all $(0)$ to extreme (10). In addition, they were asked to record whether they felt the CWI or TNI control condition assisted or hindered their recovery from the interval running session (i.e., yes or no response) and whether CWI or TNI condition would benefit their subsequent cycling training performance (i.e., yes or no response).

\section{Biochemical Recovery}

Immediately after the assessment of psychological recovery, blood was collected for the assessment of inflammation and muscle damage to be used as an indication of recovery. An 8-ml serum separator tube of blood was collected from the antecubital vein using a winged cannula attached to a vacutainer (Becton Dickinson Rutherford, NJ, USA) bleeding system. The samples were centrifuged for 15 minutes at $1,000 \mathrm{~g}$, and the supernatant from each tube was then transferred to four 1.5-ml microcentrifuge tubes (Eppendorf, North Ryde, Australia) and transported in a refrigerated transport pack for analysis at the Australian Institute of Sport Biochemistry Laboratory (Canberra, Australia).

Myoglobin $(\mathrm{MB}$, coefficient of variation $[\mathrm{CV}]=7.3 \%)$, interleukin-6 (IL-6, CV = 5.1\%), and interleukin-10 (IL-10, $\mathrm{CV}=9.9 \%)$ were analyzed by chemiluminescenceimmunometric assay (Immulite; DPS, Los Angeles, CA, USA). Plasma creatine kinase $(\mathrm{CK} ; \mathrm{CV}=0.6 \%)$ and lactate dehydrogenase $(\mathrm{LDH} ; \mathrm{CV}=0.8 \%)$ activity were determined using an enzymatic assay (Roche Diagnostics, Mannheim, Germany), whereas fatty acid-binding protein (FABP; CV $=2.4 \%$ ) was measured by an enzyme-linked immunoabsorbant assay (Hycult Biotechnology, Uden, The Netherlands).

\section{Cycling Performance}

Cycling performance during the second testing session of each condition was assessed by mean power output $\left(\mathrm{W} \cdot \mathrm{kg}^{-1}\right)$, which was measured using calibrated SRM cranks (Schoberer Rad Messtechnik GmbH, Jülich, Germany). Additionally, $\mathrm{HR}, \mathrm{La}, \dot{\mathrm{VO}}_{2}$, and $\mathrm{RPE}$ were monitored during the cycling session. Heart rate, La, and RPE were obtained at the completion of the 5 minutes at $1.5-\mathrm{W} \cdot \mathrm{kg}^{-1}$ and $3-\mathrm{W} \cdot \mathrm{kg}^{-1}$ workloads in the warm-up, the 5 -minute performance test and after each 5-minute interval during the cycling training set. $\dot{\mathrm{V}}_{2}$ peak was taken as the highest 60 -second average recorded during the performance test and the 5-minute periods at $1.5 \mathrm{~W} \cdot \mathrm{kg}^{-1}$ and $3 \mathrm{~W} \cdot \mathrm{kg}^{-1}$ in the warm-up. The La to RPE (La:RPE) ratio was obtained by dividing La concentration by RPE and multiplying by 100 and was determined for each of the five 5-minute intervals in the training set. 


\section{Statistical Analyses}

To compare the effect of CWI and TNI on recovery from intensive interval running and subsequent cycling performance, $\log$ transformation was used to express effects as percent changes for the blood and performance measures. Precision of the estimate was assessed for each dependent variable using $90 \%$ confidence limits and the chance that the true (unknown) effect was practically beneficial or harmful. The magnitude of the smallest worthwhile effect was calculated for each variable as $0.2 \times$ between-subject $S D(10)$. Magnitude-based inferences were made using the approach previously described for sports performance research (3). Briefly, if the chance of benefit and harm were both $>5 \%$, the true effect was assessed as unclear (true effect could either increase or decrease performance). Otherwise, quantitative chances of increase or decrease were assessed qualitatively as follows: $<1 \%$, almost certainly not, $1-5 \%$, very unlikely; $5-25 \%$, unlikely; 25-75\%, possible; 75-95\%, likely; 95-99\%, very likely; $>99 \%$, almost certain. The perceptual responses of physical and mental recovery, leg soreness, and fatigue and the RPE measures were analyzed using analysis of variance with significance set at $p<0.05$. Cohen effect sizes (Cohen's $d$ ) were also calculated for the perceptual measures. Effect size results were interpreted as previously described (10) with effect sizes of $<0.2$ classified as trivial, $0.2-0.5$; small, $0.5-0.8$; moderate; $>0.8$ as large.

\section{RESUlts}

In the CWI condition, there were enhancements of all measures associated with the 6 - $\times 5$-minute cycling interval training set (Table 1). The effects of CWI on the mean power output, the La response, RPE, and the La:RPE ratios during the training set are shown in Figure 1. Analysis of changes (mean change; $\pm 90 \%$ confidence limits) revealed a likely beneficial effect for La (18\% higher; $\pm 18.1 \%)$; mean power output in $\mathrm{W} \cdot \mathrm{kg}^{-1} ; 2.1 \%$ higher $( \pm 1.7 \%)$, RPE; $-1.6 \%$ lower (1.9\%), La:RPE; $19.8 \%$ higher $( \pm 17.5 \%)$, and a possible beneficial effect for HR; $1.6 \%$ higher $( \pm 1.1 \%)$ during the cycle interval training set. The effect of CWI on mean power output $\left(\mathrm{W} \cdot \mathrm{kg}^{-1}\right)$ during the 5-minute maximal effort cycling performance trial was very unlikely; $1.5 \%$ higher $( \pm 1.7 \%)$, and there was no difference in $\mathrm{V}_{2}$ peak between treatments (71.2 and $71.1 \mathrm{ml} \cdot \mathrm{kg}^{-1} \cdot \mathrm{min}^{-1}$ for CWI and TNI, respectively).

The effects of CWI on perception of mental and physical recovery, leg soreness, and fatigue are shown in Figure 2. Cold-water immersion had a moderate effect on increasing the perception of physical recovery $(d=0.58, p=0.17)$ and reducing the perception of leg soreness $(d=-0.77, p=0.08)$ and a large effect on reducing the perception of fatigue $(d=$ $-0.85, p=0.13)$. Cold-water immersion had a trivial effect on the perception of mental recovery $(d=0.13, p=0.85)$. Cold-water immersion had a small effect on RPE, reducing the perceived effort during the training set $(d=-0.36, p=$ 0.19). Furthermore, all 7 subjects responded that they believed CWI to be more effective and preferable than the TNI condition assisting their recovery from the interval running session they believed that it would benefit the cycling training performance.

Table 2 shows the effects of CWI on FABP, CK, LDH, MB, IL-6, and IL-10. Cold-water immersion was observed to have a likely beneficial effect on Il-10, 20\% higher ( $\pm 13.4 \%)$ although the effect was unclear for the other measures.

\section{Discussion}

The purpose of this study was to investigate the effect of CWI on physiological, psychological, and biochemical markers of recovery and subsequent cycling performance after intensive interval running training in high-performance triathletes. The major finding of this study was that compared with TNI, CWI had a likely beneficial effect on mean power output during subsequent cycling interval training performance but not 5-minute cycling test performance after interval running training. Furthermore, CWI had no significant effect on the perceptual responses, and IL-10 was the only blood measure that was likely changed after the CWI.

To the best of our knowledge, no previous study has examined the physiological and performance effects of CWI on the capacity to perform subsequent training in highperformance triathletes. In the present study, the triathletes were able to maintain a higher power output (2.1\%) during the cycling interval training set after the CWI compared with TNI. Importantly, $6 / 7$ athletes improved their subsequent cycling training performance in the CWI condition. Additionally, the higher power output in the CWI condition resulted in a higher lactate response, whereas RPE was lower than in the TNI condition. Taken together, these results indicate a plausible link between greater subsequent training power outputs enabled by the small alleviation in effort perception. This finding may provide support for models of fatigue that emphasize the importance of the brain and psychological processes in the regulation of performance (24).

Although the mechanism for this beneficial effect is speculative and requires further investigation, the present data are consistent with previous studies that have reported a lower perception of fatigue after exercise when water immersion was used for recovery $(32,37)$. However, it is possible that the beneficial effects observed with CWI may simply be a treatment effect because no placebo group was used in the present investigation $(18,22)$. Therefore, it is possible that the reduced sensation of fatigue and improved training performance observed in the present study occurred because the subjects believed that CWI was beneficial for recovery (4).

Furthermore, as the control condition in the current investigation also involved immersion, it may be that perceived recovery was also enhanced in the TNI condition due to hydrostatic pressure. Indeed, in a previous study, 10 
minutes of bathing at $30^{\circ} \mathrm{C}$ reduced perceptions of fatigue in male university students after submaximal cycling (26). Although it is possible that recovery was enhanced in both conditions, it remains that CWI was more effective than TNI. This increased effectiveness of CWI may be a result of the analgesic effects of cryotherapy (8).

In this study, the 5-minute maximal effort cycling test performance was not changed 9 hours after CWI when compared with the TNI condition. In contrast with the present finding, Lane and Wenger (22) reported that CWI of the legs after an 18-minute high-intensity intermittent cycling bout improved the performance of non-elite cyclists when they repeated the same protocol 24 hours later. However, in agreement with the present results, Wilcock et al. (38) reported that when the improvement in total work reported by Lane and Wenger (22) was converted to an effect size, the beneficial effect of CWI on performance was trivial $(d=0.16)$. Others have demonstrated that cycling power output may be reduced when CWI is used during a 60 minute break between 2 maximal 30 -second sprints (11). The most likely explanation for decreased maximal sprint performance after CWI is that the cold water lowers the muscle temperature and slows energy metabolism (15) and neural conduction velocity $(14,19)$. Although speculative, these effects of CWI may have affected the power output during the initial stages of the first 5-minute all-out effort in the interval set in the present study. It is possible that the initial 5-minute cycling bout would have rewarmed the muscle during the subsequent interval efforts in the training set. On the basis of these observations, we suggest that CWI treatment (i.e., type, timing, and dosage) should be matched to the event in which the athlete is performing. Indeed, the research suggests that the shorter the period of time between exercise bouts, the more beneficial CWI may be (16). Care must however be taken as CWI may impair performance in short-duration maximal effort events $(11,33)$.

In the present investigation, CWI had no significant effect on perception of mental and physical recovery, leg soreness, and fatigue when compared with the TNI group. However, there was a large effect on lowering the perception of fatigue $(d=-0.85)$ and a moderate effect for leg soreness $(d=$ -0.77 ) with CWI. These results may explain why all 7 subjects rated CWI as more effective and preferable than the TNI condition. Although nonsignificant, the reduced perception of fatigue and leg soreness and the lower RPE during the training set may help to explain why CWI improved the training set performance but not the maximal effort. It has previously been suggested that high-performance athletes may be able to produce "one-off" maximal effort performances close to their best even when fatigued (12). Therefore, it is possible that there is an effect of CWI compared with the TNI treatment, such that the small reduction in effort perception during the cycling training set enabled the subjects to regulate their effort to perform more work as the set progressed.
Changes in muscle damage marker activity have previously been observed after different hydrotherapy treatments and have been suggested to be associated with enhanced recovery (36). However, the results of the current investigation do not show any clear effect of CWI on any of the examined markers of muscle damage (FABP, CK, LDH, and MB) when compared with the TNI condition. This may be a result of the timing of sampling 9 hours after treatment, as some markers of muscle damage have been shown to peak 24 hours after exercise (36). Consistent with previous research $(1,9)$, there was a high intersubject variability in these measures in the current study, which may explain why no consistent change was observed.

It has previously been proposed that CWI may enhance recovery by reducing edema and inflammation after exercise induced muscle damage (38). In support, the present finding that CWI increased IL-10 activity suggests that cold water has a positive effect on reducing inflammation by increasing the activity of IL-10. Interleukin-10 is an anti-inflammatory cytokine capable of inhibiting proinflammatory cytokines such as IL-6, with an increase in IL-10 activity possibly expected to restrict the magnitude and duration of the inflammatory response to exercise (28). In the current investigation, the effect of CWI on IL-6 was unclear. It is likely that the timing of sampling 9 hours after CWI could not examine acute changes in inflammation that may have occurred, as this cytokine has been shown to peak 3-6 hours after exercise (28).

In summary, CWI after intensive running resulted in a likely beneficial enhancement of power output during subsequent cycling training performance in high-level triathletes compared with TNI. Cold-water immersion may have improved subsequent cycling training performance by reducing the RPE and thus enabling the subjects to cycle at higher power outputs during the subsequent training set. However, the present results suggest that CWI does not reduce muscle damage at a fast enough rate to enhance biochemical recovery for same-day performance. Thus, it seems that CWI may be more beneficial than TNI for promoting psychological recovery after intensive running training and may enhance subsequent cycling training performance later on the same day.

\section{Practical Applications}

On the basis of these present results, we suggest that coaches and scientists recommend immersion in cold water (i.e., approximately $10^{\circ} \mathrm{C},>5$ minutes intermittent immersion) rather than thermoneutral water for recovery when repeated high-intensity training sessions are required within the same day. Although CWI did not benefit single 5-minute effort maximal performance in the current investigation, the mean power over the entire interval training session was improved. Therefore, it is suggested that coaches recommend full-body immersion where possible (16) during days, where 2 intense training sessions are completed. Immersion should begin 
immediately after the first of 2 training sessions, which are separated by relatively long periods (i.e., $>6$ hours). However, the present findings contraindicate CWI before undertaking short maximal-effort cycling, as it may impair performance $(11,33)$. Additional research is required to determine the chronic effects of CWI on physiological and performance adaptations in trained athletes during longer periods of intensified training.

\section{Acknowledgments}

An Australian Sports Commission Grant supported this research.

\section{REFERENCES}

1. Bailey, D, Erith, S, Griffin, P, Dowson, A, Brewer, D, Gant, N, and Williams, C. Influence of cold-water immersion on indices of muscle damage following prolonged intermittent shuttle running. J Sports Sci 25: 1163-1170, 2007.

2. Barnett, A. Using recovery modalities between training sessions in elite athletes: Does it help? Sports Med 36: 781-796, 2006.

3. Batterham, AM and Hopkins, WG. Making meaningful inferences about magnitudes. Int J Sports Physiol Perform 1: 50-57, 2006.

4. Beedie, CJ. Placebo effects in competitive sport: Qualitative data. $J$ Sports Sci Med 6: 21-28, 2007.

5. Bishop, D, Jenkins, DG, and Mackinnon, LT. The relationship between plasma lactate parameters, $\mathrm{W}_{\text {peak }}$ and 1-h cycling performance in women. Med Sci Sports Exerc 30: 1270-1275, 1998.

6. Bleakley, C, McDonough, S, Gardner, E, Baxter, GD, Hopkins, JT, and Davison, GW. Cold-water immersion for preventing and treating muscle soreness after exercise. Cochrane Database Syst Rev, 2012.

7. Buckley, JD, Bourdon, PC, and Woolford, S. Effect of measuring blood lactate concentrations using different automated lactate analysers on blood lactate transition thresholds. J Sci Med Sport 6: 408-421, 2003.

8. Cheung, K, Hume, PA, and Maxwell, L. Delayed onset muscle soreness: Treatment strategies and performance factors. Sports Med 33: 145-164, 2003.

9. Clarkson, PM and Ebbeling, C. Investigation of serum creatine kinase variability after muscle-damaging exercise. Clin Sci (Lond) 75 : 257-261, 1988.

10. Cohen, J. Statistical Power Analysis for the Behavioral Sciences. Hillsdale, NJ: Lawrence Erlbaum Associates, 1988.

11. Crowe, M, O'Connor, D, and Rudd, D. Cold water recovery reduces anaerobic performance. Int J Sports Med 28: 994-998, 2007.

12. Dawson, B, Cow, S, Modra, S, Bishop, D, and Stewart, G. Effects of immediate post-game recovery procedures on muscle soreness, power and flexibility levels over the next 48 hours. J Sci Med Sport 8: 210-221, 2005.

13. Delextrat, A, Calleja-González, J, Hippocrate, A, and Clarke, ND. Effects of sports massage and intermittent cold-water immersion. 31: 11-19, 2013.

14. Edwards, RH. Physiological analysis of skeletal muscle weakness and fatigue. Clin Sci Mol Med 54: 463-470, 1978.

15. Ferretti, G, Ishii, M, Moia, C, and Cerretelli, P. Effects of temperature on the maximal instantaneous muscle power of humans. Eur J Appl Physiol Occup Physiol 64: 112-116, 1992.

16. Halson, SL. Does the time frame between exercise influence the effectiveness of hydrotherapy for recovery? Int J Sports Physiol Perform 6: 147-159, 2011.

17. Halson, SL, Bridge, MW, Meeusen, R, Busschaert, B, Gleeson, M, Jones, DA, and Jeukendrup, AE. Time course of performance changes and fatigue markers during intensified training in cyclists. J Appl Physiol (1985) 93: 947-956, 2002.

18. Halson, SL, Quod, MJ, Martin, DT, Gardner, AS, Ebert, TR, and Laursen, PB. Physiological responses to cold water immersion following cycling in the heat. Int J Sports Physiol Perform 3: 331-346, 2008.

19. Herrera, E, Sandoval, MC, Camargo, DM, and Salvini, TF. Effect of walking and resting after three cryotherapy modalities on the recovery of sensory and motor nerve conduction velocity in healthy subjects. Rev Bras Fisioter 15: 233-240, 2011.

20. Ingram, J, Dawson, B, Goodman, C, Wallman, K, and Beilby, J. Effect of water immersion methods on post-exercise recovery from simulated team sport exercise. J Sci Med Sport 12: 417-421, 2009.

21. Kellmann, M. Preventing overtraining in athletes in high intensity sports and stress/recovery monitoring. Scand J Med Sci Sports 20: 95-102, 2010.

22. Lane, $\mathrm{KN}$ and Wenger, HA. Effect of selected recovery conditions on performance of repeated bouts of intermittent cycling separated by 24 hours. J Strength Cond Res 18: 855-860, 2004.

23. Leeder, J, Gissane, C, van Someren, K, Gregson, W, and Howatson, G. Cold water immersion and recovery from strenuous exercise: A meta-analysis. Br J Sports Med 46: 233-240, 2012.

24. Marcora, SM. Do we really need a central governor to explain brain regulation of exercise performance? Eurn J Appl Physiol 104: 929931, 2008.

25. Montgomery, PG, Pyne, DB, Hopkins, WG, Dorman, JC, Cook, K, and Minahan, CL. The effect of recovery strategies on physical performance and cumulative fatigue in competitive basketball. J Sports Sci 26: 1135-1145, 2008.

26. Nakamura, K, Takahashi, H, Srhmai, S, and Tanaka, M. Effects of immersion in tepid bath water on recovery from fatigue after submaximal exercise in man. Ergonomics 39: 257-266, 1996.

27. Parouty, J, Al Haddad, H, Quod, M, Leprítre, PM, Ahmaidi, S, and Buchheit, M. Effect of cold water immersion on $100-\mathrm{m}$ sprint performance in well-trained swimmers. Eur J Appl Physiol 109: 483490, 2010.

28. Pedersen, BK. Special feature for the Olympics: Effects of exercise on the immune system: Exercise and cytokines. Immunol Cell Biol 78: 532-535, 2000.

29. Pointon, $M$ and Duffield, R. Cold water immersion recovery after simulated collision sport exercise. Med Sci Sports Exerc 44: 206-216, 2012.

30. Pournot, H, Bieuzen, F, Duffield, R, Lepretre, PM, Cozzolino, C, and Hausswirth, C. Short term effects of various water immersions on recovery from exhaustive intermittent exercise. Eur J Appl Physiol 111: 1287-1295, 2011.

31. Rowsell, GJ, Coutts, AJ, Reaburn, P, and Hill-Haas, SV. Effect of cold-water immersion on physical performance between successive matches in junior high-performance soccer players. J Sports Sci 27 : 565-573, 2009.

32. Rowsell, G, Coutts, A, Reaburn, P, and Hill-Haas, S. Effect of postmatch cold-water immersion on subsequent match running performance in junior soccer players during tournament play. J Sports Sci 29: 1-6, 2011.

33. Schniepp, J, Campbell, TS, Powell, KL, and Pincivero, DM. The effects of cold-water immersion on power output and heart rate in elite cyclists. J Strength Cond Res 16: 561-566, 2002.

34. Stanley, J, Buchheit, M, and Peake, JM. The effect of post-exercise hydrotherapy on subsequent exercise performance and heart rate variability. Eur J Appl Physiol 112: 951-961, 2012.

35. Vaile, J, Halson, S, Gill, N, and Dawson, B. Effect of hydrotherapy on recovery from fatigue. Int J Sports Med 29: 539-544, 2008.

36. Vaile, J, Halson, S, Gill, N, and Dawson, B. Effect of hydrotherapy on the signs and symptoms of delayed onset muscle soreness. Eur $J$ Appl Physiol 102: 447-455, 2008. 
37. Vaile, JM, Gill, ND, and Blazevich, AJ. The effect of contrast water therapy on symptoms of delayed onset muscle soreness. J Strength Cond Res 21: 697-702, 2007.

38. Wilcock, IM, Cronin, JB, and Hing, WA. Water immersion: Does it enhance recovery from exercise? Int J Sports Physiol Perform 1: 195206, 2006.

39. Yamane, M, Teruya, H, Nakano, M, Ogai, R, Ohnishi, N, and Kosaka, M. Post-exercise leg and forearm flexor muscle cooling in humans attenuates endurance and resistance training effects on muscle performance and on circulatory adaptation. Eur J Appl Physiol 96: 572-580, 2006.

40. Yeargin, SW, Casa, DJ, McClung, JM, Knight, JC

Healey, JC, Goss, PJ, Harvard, WR, and Hipp, GR. Body cooling between two bouts of exercise in the heat enhances subsequent performance. J Strength Cond Res 20: 383-389, 2006. 